\title{
The clinical evaluation of vertical root fracture after endodontic treatment with mineral trioxide aggregate
}

\author{
Nobuyuki Tani-Ishii*, Noriko Mutoh, Koichiro Muromachi and Jiro Suzuki \\ Department of Pulp Biology and Endodontics, Graduate School of Dentistry, Kanagawa Dental University, Yokosuka, Japan
}

\begin{abstract}
Introduction: Vertical root fractures (VRFs) in endodontic treatment teeth are most serious complication. VRFs have a poor prognosis and usually result in tooth extraction. The purpose of this study was to evaluate the clinical outcomes of mineral trioxide aggregate (MTA) - filled teeth for VRFs using by dental operate microscope (DOM).

Methods: Fifty-two endodontic treatment teeth with VRFs were evaluated. 52 VRFs teeth were examined and evaluated the clinical finding with radiography, and DOM finding in root canal. The MTA-filled adhesion methods consist of the elimination of infected dentin by ultrasonic root canal instrument under DOM. The elimination of infected dentin method could be expected to inhibit the root perforation using an apex locator for measuring the distance to the tooth root surface
\end{abstract} during grooving for enlarging the tooth crack and fracture.

Results: 52 VRFs teeth were treated by this method under ODM. Clinical symptoms and radiographic appearance of bony lesions were followed-up from 8 to 90 months. The survival rate of treatment was $94.3 \%$.

Conclusion: The results showed the MTA-filled adhesion methods using DOM and ultrasonic instrument was effective therapy for vertical root fractures teeth without extraction of the tooth.

\section{Introduction}

Vertical root fractures (VRFs) of endodontic treatment teeth are often encountered in the dental retreatment [1]. Clinical diagnosis of VRFs is difficult because in only a few cases can the presence of a fracture line be detected correctly with radiographic or oral examination. The prognosis of teeth with VRFs is hopeless, and these teeth usually require the extraction of tooth or resection of the affected root. Main factors which lead to extraction are bacterial infection in the fracture line, as well as resorption of nearby alveolar bone. However, an early is necessary to avoid excessive bone loss, which can impair reconstructive procedures should implant therapy be the treatment of choice.

Although several treatment approach have been used to preserve VRFs cases, such as utilizing $\mathrm{CO}_{2}$ laser to fuse VRFs [2], and intentional re-plantation with adhesive resin cement [3-5], no specific treatment has been provided ideal long term results. VRFs reconstruction with adhesive resin cement has shown successful outcome in several studies [6-9]. The distance between separated fragments, vertical bone defect localization, the position and the extent of the fracture are important factors to determine the treatment modality.

MTA might have a profound advantage when used as canal obturation material because of its superior physiochemical and bioactive properties. MTA also provides an effective seal against dentin and cementum and promotes biologic repair and regeneration of the periodontal ligament [10-13]. Furthermore, MTA has been shown to support the tooth structure and increase its obturate immature sheep teeth and standardized models of immature teeth made from bovine teeth and bovine femur bone [14]. Recently research has demonstrated that root canal treated teeth obturated with MTA exhibit higher fracture resistance than their untreated counter parts [15].
Recent research on immature tooth models that were obturated with MTA and tested for fracture strength by using an Instron testing machine indicated that at 1 year, MTA showed higher fracture resistance than untreated control $[16,17]$. MTA increase the resistance to VRFs of endodontically treated teeth and influences the mode of fracture. Furthermore, recently reports might indicate that the combination of calcium hydroxide therapy followed by the obturation of teeth with MTA and combined with a composite core might increase the longterm prognosis for teeth with open apices and necrosis pulps [18-20].

Thus, early identification of VRFs by dental operate microscope (DOM) and reconstruction with MTA are important for prognosis of VRFs cases. The purpose of this study was to evaluate the clinical outcomes of MTA-filled teeth for VRFs using by ODM.

\section{Materials and methods}

\section{Study population and clinical finding}

The study was approval by the Ethics Committee of Kanagawa Dental University and was conducted in full accordance with ethical principles, including the Declaration of Helsinki. The study protocol, the procedures and the possible risks were thoroughly explained to

Correspondence to: Dr. Nobuyuki Tani-Ishi, Department of Pulp Biology and Endodontics, Graduate School of Dentistry, Kanagawa Dental University, 82 Inaoka-cho,Yokosuka, Japan, 238-8580, E-mail: n.ishii@kdu.ac.jp

Key words: vertical root fracture, clinical outcomes, MTA, dental operate microscope

Received: May 02, 2017; Accepted: May 23, 2017; Published: May 26, 2017 
the patients, and written informed consent statements were received. The UMIN trial was registered at national medical schools in Japan, sponsored by the Ministry of Education, Culture, Science, Sports and Technology (MEXT), Japan (Clinical Trials.gov.) \#R000030480 and Current Controlled Trials UMIN000026540.

Fifty two patients who had root canal treatment completed on their VRFs teeth, at Kanagawa Dental University from May 2006 to June 2015, were recalled from 6 to 90 months review by two endodontists. Fifty two VRFs teeth in 52 patients ( $24-62$ years) with percussion pain and clinical symptoms suggestive of VRF teeth were included in the study after informed consent was obtained. A total of 52 VRFs teeth were examined and evaluated the clinical finding with radiography. VRFs were diagnosis by detection of the fracture line with visual inspection under x8.0 - x16.0 magnification by DOM finding in root canal treatment.

\section{Treatment method}

A total of 52 VRF teeth were sealed through the root canal obturation without tooth extraction. Firstly, Root-canal treatment was performed with rubber dam isolation under DOM. All root canal was established the working length to fracture areas, the infected dentin or obturation material was eliminated using \#3-5 Gates-Glidden drill (MANI Co., Utsunomiya, Japan) or Peeso reamer (MANI Co.,), and ultrasonic ENDO file (SC.4, OSADA Co., Tokyo, Japan) devices. Infected dentin was stained by $1 \%$ acid red in propylene glycol (Kuraray Co., Tokyo, Japan). The elimination of infected dentin method could be expected to inhibit the root perforation using an apex locator for measuring the distance to the tooth root surface during grooving for enlarging the tooth cracks. The root canal cleaning was performed with $5.25 \%$ sodium hypochlorite after elimination of infected dentin.

The root canal was dried with paper points, and a calcium hydroxide paste was inserted to or $1 \mathrm{~mm}$ short of the working length. When the clinical signs and symptoms subsided, crack and fracture root canal was filled with MTA. For the sealing procedures, MTA cement (Dentsply Meillfer, Switzerland) was used according to the manufacturer's instructions. To remove the smear layer without excessive modification of the underlying dentin was applied by $17 \%$ EDTA (EDTA Pentron, Tokyo, Japan) solution for 60s to the fractured surfaces and root canal and then washed and air-dried gently. MTA was delivered into the root canal by plugger or/and a MTA gun (Dentsply Meillfer, Switzerland). It was condensed with the bulky side of a sterile paper point within the premeasured length to the fracture line. After the root canal obturation of MTA, it was reattached using digital pressure applied over moist sterile cotton pallet.

Glass ionomer cement (Shofu, Kyoto, Japan) and/or provisional crowns were placed immediately after MTA obturation of the VRFs teeth. Provisional crowns were made by MMA resin (Shofu, Kyoto, Japan) in laboratory, and fixed with temporary cement (Temporary Hard Cement, Shofu). Those were beneficial for diagnostic purpose where the functional, stabilizing and occlusal parameters are developed to identify an optimal treatment result before the completion of definitive prosthesis. Percussion pain was examined after 3-6 months follow-up. Metal bonded porcelain crown or 4/5 crown, and hybrid resin crown was finally restored after completely asymptomatic, and continue to maintenance.

\section{Clinical and radiographic follow-up measurements}

The clinical finding were used to evaluate the outcome were percussion pain, sinus tract, gingival swelling, and pocket depth, and the radiographic lesion. The radiographs were exposed using a standardized long-cone technique. All the patients were recalled at an interval of 3-6 months for maintenance (Figures 1,2).

\section{Statistical analysis}

Statistical analysis was performed using Stat View (Abacus Concepts, CA, USA). Clinical parameters of the fractured teeth were compared between before treatment and after treatment at recall. Because an insufficient number of teeth were available with follow-up of more than 6 months, only the first year data were included in the statistical analysis. Differences within the groups for pain on percussion, sinus tracts, gingival swelling, increased pocket depth, the presence of radiographic lesions, and remaining tooth number were evaluated using Chi-squaire test with Yetes correction, and residual analysis, with individual variances computed for each comparison. A $P$ value $<$ 0.05 was considered to be statistically significant. Survival curves were created using the Kaplane-Meier method and the Wilcoxon t-test was used to examine differences between premolar and molar tooth group $(\mathrm{p}<0.05)$,

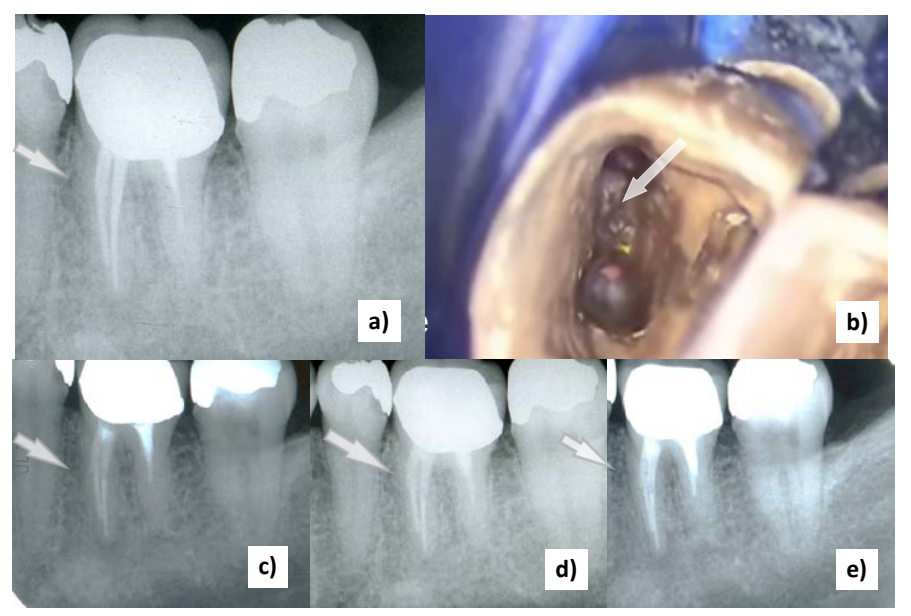

Figure 1. Perilateral radiographs changes of endodontic treatment $1^{\text {st }}$ mandibular molar with VRFs. Radiographs showing the VRFs before treatment (a) and obturation with MTA (c). Microscopic finding of fracture line (arrow) on mesial root canals (b). Follow-up radiographs showing the decrease of the radiolucent lesion areas (arrow) after treatment (d): after 6 months, e): after 60 months).

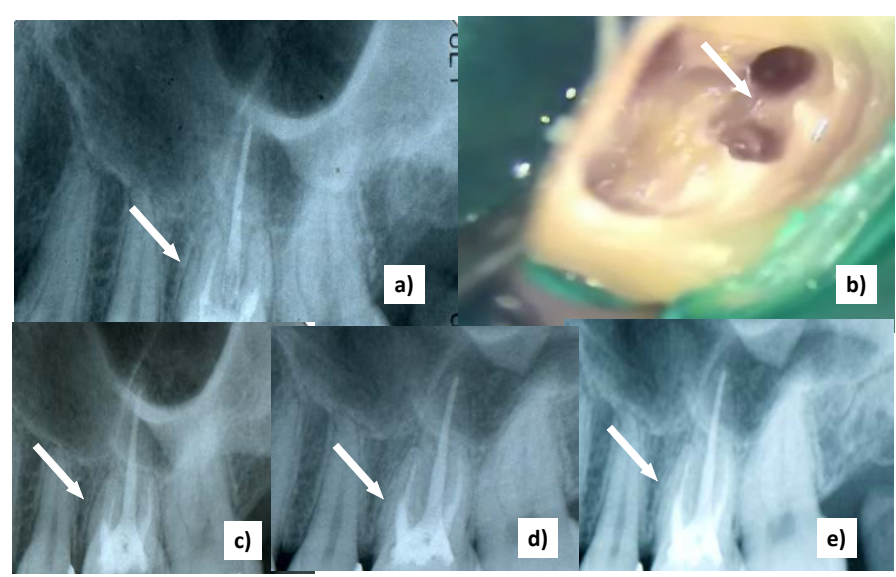

Figure 2. Enlargement of periodontal ligament space changes of endodontic treatment $1^{\text {st }}$ maxillary molar with VRFs. Radiographs showing the VRFs before treatment (a) and obturation with MTA (c). Microscopic finding of fracture line (arrow) of MB1 or MB2 canals (b). Follow-up radiographs showing the decrease of the radiolucent lesion areas (arrow) after treatment (d): after 6 months, e): after 28 months). 


\section{Results}

All VRFs teeth exhibited clinical symptoms before treatment: 52 (100\%) exhibited pain on percussion, $4(7.7 \%)$ exhibited sinus tract, $4(7.7 \%)$ exhibited gingival swelling, 4 (7.7\%) recorded pocket depths of over $4 \mathrm{~mm}$, and $52(100.0 \%)$ exhibited radiographic lesions or periodontal ligament enlargement (Table 1). All endodontic treatment VRFs with MTA were followed up until after 12 months treatment. All clinical symptoms were significantly improved after treatment with MTA. The remaining teeth were showed 49 teeth (94.3\%) after treatment with MTA.

Table 2 summarizes the 52 clinical cases (14 maxillary premolars,

Table 1. The clinical symptoms between pre-treatment and re-examination after treatment.

\begin{tabular}{|c|c|}
\hline & Number of total case $(\%)$ \\
\hline \multicolumn{2}{|l|}{ percussion pain (\%) } \\
\hline pre-treatment & $52(100.0 \%)$ \\
\hline re-examination & $3(5.7 \%)^{*}$ \\
\hline \multicolumn{2}{|l|}{ sinus tract $(\%)$} \\
\hline pre-treatment & $4(7.7 \%)$ \\
\hline re-examination & $1(1.9 \%)^{*}$ \\
\hline \multicolumn{2}{|l|}{ gingival swelling (\%) } \\
\hline pre-treatment & $4(7.7 \%)$ \\
\hline re-examination & $1(1.9 \%)^{*}$ \\
\hline \multicolumn{2}{|l|}{ pocket depth $>4 \mathrm{~m} \mathrm{~m} \mathrm{( \% )}$} \\
\hline pre-treatment & $4(7.7 \%)$ \\
\hline re-examination & $1(1.9 \%)^{*}$ \\
\hline \multicolumn{2}{|l|}{ radiographic lesion (\%) } \\
\hline pre-treatment & $52(100.0 \%)$ \\
\hline re-examination & $1(1.9 \%)^{*}$ \\
\hline \multicolumn{2}{|l|}{ remain teeth $(\%)$} \\
\hline pre-treatment & $52(100.0 \%)$ \\
\hline re-examination & $49(94.3 \%)$ \\
\hline
\end{tabular}

* Significant difference $(\mathrm{p}<0.05)$

Survival rate of MTA treatment tooth

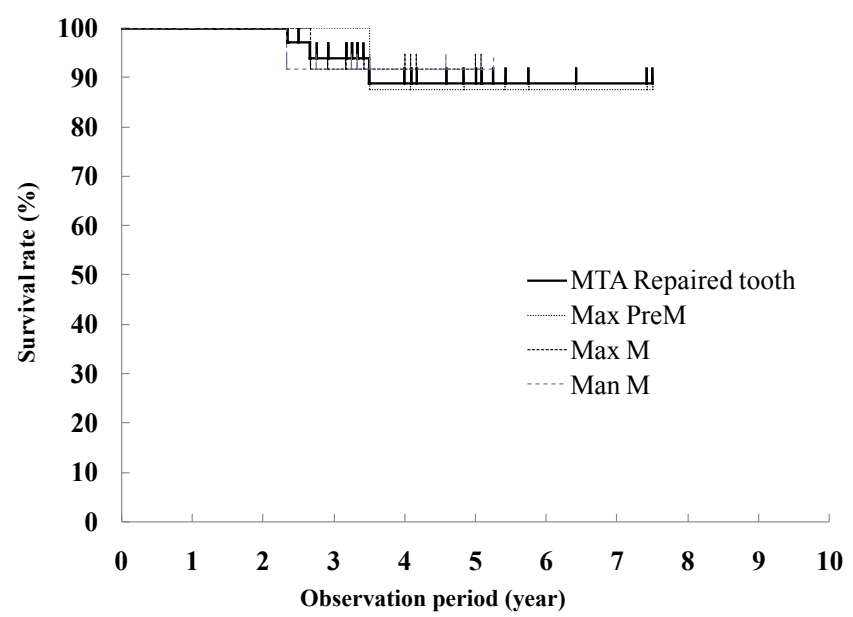

Figure 3. The Kaplane-Meier survival curve of MTA repaired teeth for VRFs teeth group. Significant difference among the tooth distribution $(\mathrm{p}=0.86)$.
20 maxillary molars, 18 mandibular molars) treated with MTA, which were examined at regular intervals for maintenance from 8 to 90 months after treatment. After 12 months, one maxillary molar was treated by hemi-section due to re-fracture or the presence of a sinus tract. The remaining teeth caused no discomfort and were asymptomatic over a mean period of $38.9 \pm 22.9$ months (range 8-90 months).

The Kaplan-Meier survival curve is shown in Figure 3. The 7-year survival rates of MTA repaired all teeth were $88.8 \%$. The 5-year survival rates of MTA repaired teeth (maxillary premolar: $88.8 \%$, maxillary molars: $91.7 \%$, mandibular molars: $91.7 \%$ ) was not significant difference among the tooth distribution $(\mathrm{p}=0.86)$.

\section{Discussion}

MTA is the most biocompatible endodontic cement material, able to promoting tissue regeneration [21-23]. Recently, MTA was used for root fracture repair. The use of MTA in intra-alveolar root fractures was described in some case reports. Eraden et al. [24] and Kusgoz et al. [25] reported the repair of horizontal root fracture sealing with MTA. During a follow-up period of 1 to 3 years, all teeth showed excellent clinical and radiographic healing. Yildirin and Gencoglu observed that the area of the MTA and fracture line was fully surrounded with new hard tissue formation. Healing with the interposition of connective tissue was found in the 10-year follow-up radiographic although MTA was extruded between the fragment [26]. Kim et al initially identified 22 teeth in 21 patients who had horizontal intra-alveolar root fractures and who had received endodontic treatments with MTA, 17 teeth exhibited healing of the root fracture and 2 teeth showed interposition of granulation tissue [27].

Furthermore, Taschieri et al. reported that 10 incomplete vertical root fracture repair surgical procedures were performed [28]. At 12-months follow-up, all cases remained successful. Hadrossek et al also reported the re-implantation with MTA repair VRFs teeth could be kept in situ after 2 years [29]. Those data shows MTA was recommend to repair VRFs by preparing a groove along the entire vertical fracture, placing MTA in the groove, and covering it with a resolving membrane.

This study follows the long-term treatment and check-ups of the intra-oral cementation of 52 VRFs teeth after restored with MTA obturation. The total of $49(94.3 \%)$ teeth were improved the clinical symptoms, and continue to the occlusal function after restoration. Our data shows that VRFs teeth treated by MTA may be functioned successfully from 8 to 90 months period. The results favorable factors in the present study, the infection removal, the biological affinity and the adhesive force of MTA can be considered. Infected root canal treatment of principle, it is needless to say that in the removal of root canal infection source. It is considered the infected dentin removal in the VRFs will affect the clinical outcome. In the treatment protocol, infection dentin removed until just before the periodontal ligament around fractures or crack was visible in the enlarged field of view through the use of DOM. As much as possible removal of the infected dentin is related to also lead to the strengthening of the MTA

Biocompatibility of MTA for periodontal tissue has been reported

Table 2. The summary of endodontic treatment cases with MTA for VRFs teeth.

\begin{tabular}{|c|c|c|c|c|}
\hline Tooth type & $\begin{array}{c}\text { The number of } \\
\text { treatment cases }\end{array}$ & $\begin{array}{c}\text { Recall terms (months) } \\
(\mathbf{m e a n} \pm \text { SD) }\end{array}$ & $\begin{array}{c}\text { The number of } \\
\text { failure cases (\%) }\end{array}$ \\
\hline Maxillary Premolar & 14 & $10 \sim 90(47.4 \pm 25.5)$ & $13(92.9)$ \\
\hline Maxillary Molar & 20 & $8 \sim 61(32.5 \pm 15.8)$ & $19(95.0)$ \\
\hline Mandibular Molar & 18 & $8 \sim 63(32.6 \pm 16.9)$ & $17(94.4)$ \\
\hline Total & 52 & $8 \sim 90(38.9 \pm 22.9)$ & $1(5.0)$ \\
\hline
\end{tabular}


and has been considered sufficient for use in soft tissue in procedures such as intentional replantation, retro-filling in root surgery, and repair of the perforation. MTA is a bioactive silicate cement is nonirritating to periapical tissue and also induces and also induces the regeneration of cementum and the PDL [30-33]. MTA can stimulate hard tissue deposition when used as a root-end filling materials [34]. When the cement was experimentally placed as a root-end filling in dogs or nonhuman primates, the histologic regeneration of the periodontal architecture was a frequent finding $[35,36]$. Several studies have shown that MTA placed as a root-end filling material promotes the regeneration of the PDL through a complex process of biologic repair $[32,37]$. Histological sections revealed biologic closure by the synthesis of new cementum and the regeneration of the PDL in the absence of inflammation.

Furthermore, MTA might stimulate PDL fibroblasts to display the osteogenic phenotype and promote the production of osteonectine, osteopontine, and increase alkaline phosphatase levels [38,39]. Our data shows that all treatment case was improved the percussion pain after until 6 months. Those clinical symptoms were support from the resistance to vertical root fracture of roots. MTA-obturation root canals demonstrated a significantly greater resistance to vertical root fracture. This can be explained as follows: MTA sets through a hydration reaction of the calcium silicates, which forms a colloidal gel that turns that into a hard structure in $2 \mathrm{~h} 45 \mathrm{~min}$ [13]. This setting reaction is complex but mainly involves the formation of di-calcium and tri-calcium silicate hydrates rapidly and is responsible for the increase in strength over the subsequent week [40]. I $t$ is likely that tissue fluid may penetrate through these tubules and reach the MTA root filling. The result is the formation of a hydroxyapatite-like layer at the interface between dentine and MTA root fillings as demonstrated previously [41].

Tooth crack and VRFs in endodontic treated teeth are most serious complication, and VRFs have a poor prognosis and usually result in tooth extraction. In the present study, it is the first report to observe the long-term clinical results as an intra-oral cementation method with MTA obturation for VRFs tooth. The success rates of $94.3 \%$ allow this method to be a reliable option for restoring missing teeth. In conclusion, these results showed the MTA-obturation adhesion methods using ODM and ultrasonic instrument was effective therapy for vertical root fractures teeth without extraction of the tooth.

\section{Acknowledgements}

This study was supported by a part of Grant-in-Aid for Scientific Research from the Ministry of Education, Culture, Sports, Science and Technology of Japan (B) (No. 20390437). The authors deny any conflicts of interest related to this study.

\section{References}

1. Morfis AS (1990) Vertical root fractures. Oral Surg Oral Med Oral Pathol 69: 631-635. [Crossref]

2. Dederich DN (1999) CO2 laser fusion of a vertical root fracture. J Am Dent Assoc 130: 1195-1199. [Crossref]

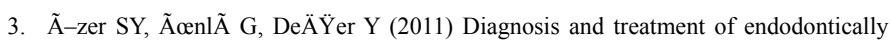
treated teeth with vertical root fracture: three case reports with two-year follow-up. $J$ Endod 37: 97-102.

4. M. Hayashi, Y. Kinomoto, M. Miura, L. Sato, F. Takeshige, and S. Ebisu (2002) Shortterm evaluation of intentional replantation of vertically fractured roots reconstructed with dentin-bonded resin. $J$ Endod 28: 120-4.

5. F. Arikan, M. Franko, and A. Gürkan (2008) Replantation of a vertically fractured maxillary central incisor after repair with adhesive resin. Int Endodon 41:73-79.
6. Hayashi M, Kinomoto Y, Takeshige F, Ebisu S (2004) Prognosis of intentional replantation of vertically fractured roots reconstructed with dentin-bonded resin. $J$ Endod 30:145-148.

7. Oztürk M, Unal GC (2008) A successful treatment of vertical root fracture: a case report and 4-year follow-up. Dent Traumatol 24: e56-60. [Crossref]

8. Nizam N, Kaval ME, GÃrlek Ã, Atila A, ÃalÄÅŸkan MK2 (2016) Intentional replantation of adhesively reattached vertically fractured maxillary single-rooted teeth. Int Endod J 49: 227-236. [Crossref]

9. Sugaya T, Kawanami M, Noguchi H, Kato H, Masaka N (2001) Periodontal healing after bonding treatment of vertical root fracture. Endod Dent Traumatol 17:174-9.

10. Torabinejad M, Watson TF, Pitt Ford TR (1993) Sealing ability of a mineral trioxide aggregate when used as a root end filling material. J Endod 19:591-5.

11. Torabinejad M, Higa RK, McKendry DJ, Pitt Ford TR (1994) Dye leakage of four root end filling materials: effects of blood contamination. J Endod 20:159-63.

12. Torabinejad M, Smith PW, Kettering JD, Pitt Ford TR (1995) Comparative investigation of marginal adaptation of mineral trioxide aggregate and other commonly used root-end filling materials. J Endod 21: 295-9.

13. Torabinejad M, Hong CU, McDonald F, Pitt Ford TR (1995) Physical and chemical properties of a new root-end filling material. $J$ Endod 21: 349-353. [Crossref]

14. Cauwels RG, Pieters IY, Martens LC, Verbeeck RM (2010) Fracture resistance and reinforcement of immature roots with gutta percha, mineral trioxide aggregate and calcium phosphate bone cement: a standardized in vitro model. Dent Traumatol 26: $137-42$.

15. Bortoluzzi EA, Souza EM, Reis JM, Esberard RM, Tanomaru-Filho M (2007) Fracture strength of bovine incisors after intra-radicular treatment with MTA in an experimental immature tooth model. Int Endod J 40: 684-91.

16. Hatibovic-Kofman S, Raimundo L, Chong L, Moreno J, Zheng L (2006) Mineral trioxide aggregate in endodontic treatment for immature teeth. Conf Proc IEEE Eng Med Biol Soc 1: 2094-7.

17. Hatibovï̈ Kofman S, Raimundo L, Zheng L, Chong L, Friedman M, et al. (2008) Fracture resistance and histological findings of immature teeth treated with mineral trioxide aggregate. Dent Traumatol 24: 272-276. [Crossref]

18. Saupe WA, Gluskin AH, Radke RA Jr (1996) A comparative study of fracture resistance between morphologic dowel and cores and a resin-reinforced dowel system in the intraradicular restoration of structurally compromised roots. Quintessence Int 27:48391.

19. Katebzadeh N, Dalton BC, Trope M (1998) Strengthening immature teeth during and after apexification. J Endod 24: 256-9.

20. Pene JR, Nicholls JI, Harrington GW (2001) Evaluation of fiber-composite laminate in the restoration of immature, nonvital maxillary central incisors. J Endod 27: 18-22.

21. Torabinejad M, Chivian N (1999) Clinical applications of mineral trioxide aggregate. $J$ Endod 25: 197-205. [Crossref]

22. Mitchell PJ, Pitt Ford TR, Torabinejad M, McDonald F (1999) Osteoblast biocompatibility of mineral trioxide aggregate. Biomaterials 20: 167-73.

23. Koh ET, Torabinejad M, Pitt Ford TR, Brady K, McDonald F (1997) Mineral trioxide aggregate stimulates a biological response in human osteoblasts. $J$ Biomed Mater Res 5: 37:432-9.

24. Erdem AP, Ozdas DO, Dincol E, Sepet E, Aren G (2009) Case Series: root healing with MTA after horizontal fracture. Eur Arch Paediatr Dent 10: 110-113. [Crossref]

25. Kusgoz A, Yildirim T, Tanriver M, Yesilyurt C (2009) Treatment of horizontal root fractures using MTA as apical plug: report of 3 cases. Oral Surg Oral Med Oral Pathol Oral Radiol Endod 107: e68-72.

26. Roig M, Espona J, Mercadé M, Duran-Sindreu F (2011) Horizontal root fracture treated with MTA, a case report with a 10-year follow-up. Dent Traumatol 27: 460463. [Crossref]

27. Kim D, Yue W, Yoon TC, Park SH, Kim E (2016) Healing of Horizontal Intra-alveolar Root Fractures after Endodontic Treatment with Mineral Trioxide Aggregate. J Endod 42: $230-5$.

28. Taschieri S, Bortolin M, Weinstein T, Del Fabbro M (2011) Preservation of an injured vital tooth using ultrasonic device and mineral trioxide aggregate. Minerva Stomatol 60: 467-77.

29. Hadrossek PH, Dammaschke T (2014) New treatment option for an incomplete vertical 
root fracture--a preliminary case report. Head Face Med 10: 9. [Crossref]

30. Pace R, Giuliani V, Pagavino G (2008) Mineral trioxide aggregate as repair material for furcal perforation: case series. J Endod 34:1130-3.

31. De-Deus G, Reis C, Brandão C, Fidel S, Fidel RA (2007) The ability of Portland cement, MTA, and MTA Bio to prevent through-and-through fluid movement in repaired furcal perforations. J Endod 33: 1374-7.

32. Torabinejad M, Pitt Ford TR, McKendry DJ, Abedi HR, Miller DA, et al. (1997) Histologic assessment of mineral trioxide aggregate as a root-end filling in monkeys. Endod 23: 225-8.

33. Regan JD, Gutmann JL, Witherspoon DE (2002) Comparison of Diaket and MTA when used as root-end filling materials to support regeneration of the periradicular tissues. Int Endod J 35: 840-7.

34. Baek SH, Plenk H Jr, Kim S (2005) Periapical tissue responses and cementum regeneration with amalgam, SuperEBA, and MTA as root-end filling materials. J Endod 31: 444-9.
35. Torabinejad M, Hong CU, Lee SJ, Monsef M, Pitt Ford TR (1995) Investigation of mineral trioxide aggregate for root-end filling in dogs. J Endod 21: 603-608. [Crossref]

36. Apaydin ES, Shabahang S, Torabinejad M (2004) Hard-tissue healing after application of fresh or set MTA as root-end-filling material. J Endod 30: 21-24. [Crossref]

37. Lamb EL, Loushine RJ, Weller RN, Kimbrough WF, Pashley DH (2003) Effect of root resection on the apical sealing ability of mineral trioxide aggregate. Oral Surg Oral Med Oral Pathol Oral Radiol Endod 95:732-5.

38. Bonson S, Jeansonne BG, Lallier TE (2004) Root-end filling materials alter fibroblast differentiation. $J$ Dent Res 83: 408-413.

39. Gorduysus M, Avcu N, Gorduysus O, Pekel A, Baran Y, et al. (2007) Cytotoxic effects of four different endodontic materials in human periodontal ligament fibroblasts. $J$ Endod 33: 1450-1454. [Crossref]

40. Torabinejad M, White DJ (1995) Tooth filling material and method of use, U.S. Patent, Editor USA: Loma Linda University

41. Sarkar NK, Caicedo R, Ritwik P, Moiseyeva R, Kawashima I (2005) Physicochemical basis of the biologic properties of mineral trioxide aggregate. J Endod 31: 97-100.

Copyright: $₫ 2017$ Tani-Ishii N. This is an open-access article distributed under the terms of the Creative Commons Attribution License, which permits unrestricted use, distribution, and reproduction in any medium, provided the original author and source are credited. 